\title{
A POLÍTICA DE EDUCAÇÃO ESPECIAL DO ESTADO DO PARANÁ NAS DÉCADAS DE 1970 e 1980
}

\author{
Vera Lucia Ruiz Rodrigues da Silva ${ }^{1}$ \\ Paulino José Orso ${ }^{2}$ \\ Dorisvaldo Rodrigues da Silva ${ }^{3}$
}

UNIOESTE

\begin{abstract}
RESUMO
Este artigo aborda, de forma resumida, resultados de pesquisa realizada durante a dissertação intitulada Educação da Pessoa com Deficiência no Estado do Paraná nas décadas de 1970 e 1980: coexistência de atendimento em escolas públicas regulares e em especiais privadas/filantrópicas. Tem como objetivo compreender como o atendimento na área de educação especial foi oficializado pelo Estado, constituindo legalmente a possibilidade de oferta educacional em ambientes escolares públicos e privados/filantrópicos. O trabalho de pesquisa centrou-se em revisão bibliográfica de fontes primárias e secundárias existentes em instituições públicas, banco de dados de teses e dissertações e busca por registros documentais, como as Mensagens de Governadores apresentadas na Assembleia Legislativa do período investigado. O Estado do Paraná implementou ações relacionadas à Educação Especial, por meio de legislações estaduais que foram pautadas na Política do CENESP - Centro Nacional de Educação Especial. Deste modo, frente à concepção de pessoa com deficiência presente nas propostas de currículo destinadas para esse segmento, a expansão do atendimento em escolas especiais superou o atendimento no ensino regular.

Palavras-chaves: Educação Especial; Integração; História; Paraná.
\end{abstract}

\section{SPECIAL EDUCATION POLICY OF THE STATE OF PARANÁ IN THE DECADES OF 1970 AND 1980}

\begin{abstract}
This article addresses briefly the results of research carried out for the dissertation entitled Educação da Pessoa com Deficiência no Estado do Paraná nas décadas de 1970 e 1980: coexistência de atendimento em escolas públicas regulares e em especiais privadas/filantrópicas (Education of People with Disabilities in the State of Paraná in the decades of 1970 and 1980: coexistence of service in regular public schools and in special private/philanthropic schools). It aims to examine how the service in the field of special education was made official by the State, constituting the legal possibility of educational offer in public and private/philanthropic schools. Research focused on literature review of primary and secondary sources from public institutions, theses and dissertations database and documentary records, such as the Governors Messages transmitted in the Legislative Assembly in the period under investigation. The State of Paraná implemented actions related to Special Education through state laws guided by the policies set by CENESP (National Center for Special Education). Given the conception of person with disabilities in the curriculum guidelines directed to this segment, the expansion of service in special schools surpassed the attendance in regular education.
\end{abstract}

Keywords: Special Education; Integration; History; Paraná. 


\section{Introdução}

Este artigo apresenta uma síntese da pesquisa realizada durante o mestrado em Educação na Universidade Estadual do Oeste do Paraná (UNIOESTE), a qual buscou desvelar como a oferta educacional às pessoas com deficiência na Educação Especial no Paraná coexistiu no setor público e filantrópico/privado. O período investigado compreendeu as décadas de 1970 e 1980.

O estudo da Educação Especial no Paraná, nas décadas de 1970 e 1980, justifica-se pelo fato de que o encaminhamento realizado na esfera nacional propiciou desdobramentos nesse estado, percorrendo caminhos entrelaçados ao que estava posto nas esferas nacional e internacional, pautando-se nos princípios da normalização, integração e individualização que regeram essa área da educação no Brasil, que se serviu dos princípios constantes na Educação Especial dos países escandinavos da década de 1950 (PARANÁ, 1994).

A partir da análise do material bibliográfico da pesquisa, reconhecem-se personagens que estavam à frente da política voltada à Educação Especial no Paraná, bem como das ações e dos desdobramentos para consolidação do atendimento nessa área. A gestão da Educação Especial nesse estado, nas décadas de 1960 a 1980, foi executada por diretores da Secretaria de Educação responsáveis pela administração do referido serviço, sendo que, entre 1965 a 1983, Maria de Lourdes Canziani assumiu o setor de Educação Especial como sua primeira diretora. De acordo com Canziani (1985), dos anos de 1963 a 1983, desenvolveram-se atividades voltadas a estruturar o atendimento educacional da pessoa com deficiência que estava vinculado aos princípios e às tendências de âmbito nacional. Seu sucessor nessa diretoria foi Flávio Arns, que permaneceu no Departamento de Educação Especial de 1983 a 1990 (BRASIL, 2010).

A política de Educação Especial desenvolvida pelos gestores foi analisada a partir de legislações estaduais, deliberações do Conselho Estadual de Educação e relatórios de governadores apresentados na Assembleia Legislativa, produzidos naquela época. Nos documentos pesquisados, buscou-se identificar de que modo a dualidade de oferta, público e filantrópico/privado, articulada aos princípios da normalização, integração e individualização, foi sendo concretizada nas diretrizes da Educação Especial paranaense. A fim de possibilitar melhor reflexão, fez-se um levantamento estatístico, objetivando demonstrar a relação existente entre as matrículas em classes especiais de instituições publicas e privadas de ensino regular no estado do Paraná, de 1979-1987, o quantitativo de matrículas em instituições especializadas, no mesmo período, bem como o comparativo entre a evolução de estabelecimentos de Educação Especial e as de $1^{\circ}$ e $2^{\circ}$ graus do ensino regular.

\section{Desenvolvimento}

A Política Nacional para atender o segmento social das pessoas com deficiência foi estabelecida em 1973/1974 com a criação do Centro Nacional de Educação Especial (CENESP). No Paraná, entretanto, a Educação Especial já vinha sendo fomentada antes da política do CENESP. Como exemplo, citam-se: a) o Instituto Paranaense de Cegos (1939), que, a partir de 1940, ofertou escola especial para cegos; b) o Centro Educacional Guaíra (1954), localizado na cidade de Curitiba, no qual foi criada a primeira Clínica Psicológica (1956) e a primeira classe especial (1958), ambas destinadas ao atendimento da pessoa com deficiência intelectual, na época denominadas excepcionais ${ }^{4}$, trabalho liderado pela professora Pórcia Guimarães Alves (1917-2005); c) o Instituto Londrinense de Surdos, 
criado em 1959; d) a Escola Mercedes Stresser, criada em 1961 com a finalidade de atender os internos do Hospital Nossa Senhora da Luz, assistindo pessoas com deficiência mental e com transtornos mentais, por não haver, na época, distinção entre ambas; e d) a APAE de Curitiba, que iniciou o atendimento em 1962.

Inicialmente, os trabalhos realizados estavam voltados ao atendimento das pessoas com deficiência mental, sendo todas tratadas como doentes mentais, pois não havia clareza e nem distinção entre o que era compreendido como deficiência e doença. Pelos documentos analisados, observa-se que essa falta de clareza acarretava um aumento nos dados estatísticos referentes às pessoas diagnosticadas com doença mental, o que suscitou a necessidade de ampliar a assistência aos doentes mentais. Em função dessa condição, o atendimento aos doentes mentais passou a ser prioridade na política pública do estado, como se pode observar na mensagem do governador Ney Braga, em 1961: "No que se refere às doenças mentais, a situação pode ser avaliada ao vermos que, para uma necessidade mínima de cerca de 6.000 leitos, a disponibilidade atual é de apenas 1.230". (PARANÁ, 1961, p. 24-25). Para suprir essa demanda, foram realizados investimentos objetivando a descentralização do atendimento, que era realizado na capital do estado, tendo como perspectiva a criação de "dispensários para doentes mentais em Maringá, Londrina, Cornélio Procópio, Irati e Apucarana, visando atendê-los em suas localidades e evitando os seus deslocamentos para Curitiba" (PARANÁ, 1961, p. 37-38).

Devido à confusão conceitual e à prática no atendimento entre deficientes e doentes, alguns profissionais da APAE e a Sra. Canziani, após cursarem especialização em Educação Especial no Rio de Janeiro e em Madrid, iniciaram, na Escola Mercedes Stresser, em 1961, a oferta de atendimento aos denominados excepcionais, permitindo separar aqueles com diagnóstico de doentes daqueles caracterizados como deficientes.

Em âmbito governamental, a atenção ao surdo realizada na gestão de Ney Braga foi promovida por meio da criação do Instituto de Assistência ao Menor (IAM), em 1954, vinculado ao Centro de Reabilitação da Audição e da Fala Alcindo Fanaya Júnior para esse serviço de atendimento. Em 1997, esse centro passou a ser um órgão da Secretaria Estadual de Educação, recebendo status de estabelecimento de ensino e passando a ser denominado Escola Estadual do Centro de Reabilitação da Audição e da Fala Alcindo Fanaya Júnior Ensino de $1^{\circ} \mathrm{Grau}$.

Em 1963, foi criada a Secção de Educação de Excepcionais por meio do Decreto n. ${ }^{\circ}$ 10.527 (PARANÁ, 1963), Vinculada à Secretaria de Estado dos Negócios da Educação e Cultura - Departamento de Educação. Seus princípios estavam articulados com os governamentais, em que se destacava a racionalização de recursos físicos, humanos e financeiros, a igualdade de oportunidade e a ampliação do acesso à educação elementar.

A legalização dessa proposição ocorreu por meio da Lei n 4.978 (PARANÁ, 1964), de 5 de dezembro de 1964, que estabeleceu o Sistema Estadual de Ensino. Alguns aspectos seguiram a Diretriz Nacional, que influenciou a organização da Educação Especial no Paraná. Essa lei assegurou, em seu artigo $5^{\circ}$, parágrafo único, o direito de a família escolher o gênero de educação que seu filho deveria ter. Em seu artigo $6^{\circ}$, inciso I, o Estado assumiu a obrigatoriedade de ofertar o ensino em todos os graus, na forma da lei em vigor. No que diz respeito às instituições particulares, a referida lei assegurou apoio técnico e financeiro. Além disso, em seu artigo 111, estabeleceu que o Conselho Estadual de Educação deveria regulamentar a oferta educacional dos excepcionais em normas específicas.

As diretrizes educacionais da pessoa com deficiência estavam atreladas às demais demandas estaduais, fato este decorrente da relação entre formação educacional e demandas de capacitação para o mercado de trabalho. Por volta da década de 1960, de 
modo geral, a formação educacional da população estava orientada para uma formação elementar, em virtude de o mercado de trabalho não exigir trabalhadores com maior qualificação, pois a economia centrava-se no setor agrícola. De acordo com o governador Ney Braga, em 1961, 45\% de crianças em idade escolar não estavam estudando por falta de acesso à instrução básica (PARANÁ, 1961). No relato desse governador, a situação de jovens e adultos não se diferenciava, sendo que mais de um milhão destes se encontravam sem acesso à educação formal. Segundo Trintin (2006), foi na década de 1970, em face da conjuntura nacional e internacional, que o setor econômico paranaense buscou fortalecer a diversificação da economia, iniciando um processo de substituição do plantio de café por soja, trigo, milho e cana, e implantando o setor industrial.

O apoio ao setor filantrópico/privado e os regulamentos do setor público para a Educação Especial sofreram influências de outros estados, tais como São Paulo, Minas Gerais e Amazonas. As ações governamentais e não governamentais realizadas na época criou a necessidade de o governo federal definir diretrizes nacionais para a Educação Especial, que foi estabelecida a partir da criação do CENESP. As Diretrizes Básicas para Ação do CENESP foram formuladas a partir de princípios e recomendações presentes na Lei $\mathrm{n}^{\circ}$ 5.692/71 e no Plano Setorial de Educação 72-74, que previam convênios para ampliação do acesso educacional, igualdade de oportunidade, formação educacional para o trabalho e incentivo à iniciativa privada.

Porém, o estado do Paraná, na década de 1970, estava com sua produção agrícola e industrial diversificada e havia adotado o uso de tecnologias mais avançadas, consequentemente, levando à necessidade de as pessoas passarem a ter uma escolaridade mais elevada. Como assinala Gonçalves (1997), o Paraná não possuía infraestrutura suficiente para atender à demanda populacional, que aumentou significativamente no período compreendido entre 1940 e 1970. De uma população de 1.236.276, em 1940, passou-se para 6.997.682 de habitantes, em 1970.

Na década de 1970, para atender à necessidade de formação de professores também na área da Educação Especial, e para constituir um diagnóstico do quadro de pessoas com deficiência, o governo federal celebrou o convênio do Projeto Especial Multinacional de Educação Brasil-Paraguai-Uruguai (OEA - Educação Especial/1975), que realizou ações no Paraná. Outras ações em âmbito estadual foram concretizadas. Houve a criação de escolas especiais, classes especiais, salas de recursos e outros serviços paralelos à formação educacional, como a formação em cursos profissionalizantes, atendendo à reforma da Lei n ${ }^{\circ}$ 5.692/71 (PARANÁ, 1977).

No ano de 1976, foi aprovado um projeto para abertura de classes especiais para atendimento de alunos com deficiência mental nos municípios de Assis Chateaubriand, Cascavel, Palotina Céu Azul, Marechal Cândido Rondon, Toledo, Foz do Iguaçu, Ponta Grossa, Londrina, Maringá, Apucarana, Arapongas, Jacarezinho e Guarapuava (PARANÁ, 1977). Em 1979, o governo estadual realizou a triagem e avaliação pedagógica de 3.511 casos, abrangendo tanto a capital como o interior. Para a execução desse trabalho, os municípios solicitaram os serviços ao Departamento de Educação Especial (DEE/PR).

Em relação ao serviço de triagem, segundo o relatório do governador, os casos diagnosticados foram encaminhados para atendimento conforme prescrito na avaliação pedagógica. Esse atendimento poderia ser feito "nas escolas especiais, classes especiais, escolas comuns, clínicas, habilitação profissional e outros, conforme as necessidades específicas constatadas na avaliação" (PARANÁ, 1979, p.14). As atividades expressas no relatório, relacionadas à qualificação profissional dos excepcionais, contemplaram a reestruturação do Centro de Habilitação Profissional Mercedes Stresser. A Secretaria de Estado da Educação e Cultura (SEEC) também articulou a integração de alunos com 
deficiência em cursos profissionalizantes por meio de parcerias com o CENESP, o SENAC e outras instituições, para atender às áreas das deficiências.

$\mathrm{Na}$ área da deficiência visual, registra-se a realização de cursos de telefonista, datilografia, artesanato e macramé. Na área da deficiência auditiva, foram ministrados os cursos de cabeleireiro, manicure, desenho básico, cartazismo e datilografia (PARANÁ, 1979). Já na área da deficiência mental, havia alunos em cursos de datilografia, desenho básico, ajudante de costura e marceneiro auxiliar. $\mathrm{Na}$ área da deficiência física não sensorial, os alunos participaram de cursos como iniciação em serviços de escritórios, secretário auxiliar, caixa de supermercado, datilografia, auxiliar de contabilidade, eletricista e eletrônico (PARANÁ, 1979).

Observa-se que o fomento dessas atividades foi ao encontro das proposições do CENESP, estabelecidas em suas Diretrizes para Ação, no que tange à utilidade prática da formação do aluno, e também dos planos de ação do MEC e do Estado do Paraná, que atrelavam a formação educacional à qualificação de mão de obra para atividades elementares e técnicas. Outras ações foram realizadas pelo DEE para atingir a proposição de concretizar o atendimento educacional às pessoas com deficiência.

As mensagens dos governadores possibilitaram verificar que o DEE buscava articulação com o setor de ensino regular. Em 1978, foi desenvolvido o projeto Novas Metodologias, cujo propósito era realizar triagem e avaliação dos alunos matriculados nas primeiras séries do ensino de $1^{\circ}$ grau, por meio da análise de fichas de referências nessas séries. Foram avaliados 4.284 alunos, mas relatório dessas ações não apresentou os resultados da avaliação e nem os encaminhamentos realizados (PARANÁ, 1979).

Os relatórios mencionam outras secretarias que também buscaram promover atividades que integrassem as pessoas com deficiência. Por exemplo: alunos da Escola de Recuperação de Surdos-Mudos e alunos de escolas especiais participaram de cursos de pintura, desenho, entalhe, xilogravura, cerâmica, tapeçaria e fantoches, promovidos pelo Centro Juvenil de Artes Plásticas (PARANÁ, 1978).

Quanto ao financiamento da Educação Especial, pode-se expressar que o Governo do Paraná previu, em seu orçamento, verba a ser empregada nos setores público e privado. Em 1979, o setor público já havia conquistado um know-how que lhe possibilitava definir políticas de Educação Especial, de modo autônomo, sem a presença do setor privado. Entretanto, suas políticas parecem ter mantido, inclusive por princípio filosófico, a articulação com o setor privado. Tal condição estava aparentemente delineada pela questão financeira e pela comodidade e descompromisso do Estado em assumir a educação dos alunos com deficiência, já que o setor filantrópico assumia este tipo de atendimento.

O próprio relatório denominado Mensagem apresentada à Assembleia Legislativa do Estado pelo Senhor Jayme Canet Junior explicitou o aumento de investimento em escolas especiais quando se compara o ano de 1978 ao de 1977. A SEEC, para o desenvolvimento de ações na área da Educação Especial, realizou diversos convênios. Nesse sentido, o MEC, por meio do CENESP, disponibilizou recursos para bolsas de estudos aos alunos com deficiência a fim de ampliar o atendimento educacional a esse segmento social (PARANÁ, 1979). Porém, não ficou claro se essas bolsas eram para os alunos matriculados em escolas públicas e particulares, pois, ao mencionar tais recursos, o relatório abrange a rede regular de ensino (PARANÁ, 1980).

Apesar de as mensagens governamentais não terem sido consultadas ${ }^{5}$ ano a ano, devido à dificuldade de acesso a elas e ao fato de não apresentarem as informações de modo padronizado, foi possível realizar algumas observações. Tais documentos não apresentaram dados de alunos com deficiência matriculados na rede regular de ensino até 
1978. Mediante o exposto, é possível cogitar que o investimento ocorreu principalmente nas escolas especiais.

Há que se considerar, também, que existiam pessoas que necessitavam de uma educação particularizada, a qual poderia ser realizada nas classes especiais, mas não foi isso o que ocorreu com a implantação da política educacional do período, em decorrência de ter seu balizamento na política do CENESP. Essa política, por sua vez, estava pautada nos princípios e nas orientações das normatizações - como o Parecer $n^{\circ}$ 842/72, que conceituou integração educacional, e a Lei ${ }^{\circ} 5.692$ (BRASIL, 1971), que buscava uma integração socioeconômica e educacional dos excepcionais a partir de um princípio processual e gradativo (BRASIL, 1979a; 1979b; 1979c; 1979d).

A leitura das propostas curriculares para deficientes visuais, para deficientes auditivos e para deficientes mentais, que foram publicadas em 1979 (BRASIL, 1979a; 1979b; 1979c; 1979d), permitiu compreender como esse processo gradativo estava sendo concebido para cada área da deficiência. Nessas propostas, o papel das escolas especiais e das classes especiais se constituiu como uma modalidade fundamental para absorver o aluno excepcional até este estar "pronto" para ingresso no ensino regular.

Além disso, o conjunto das orientações das propostas curriculares, das leis e dos pareceres, articulado a interpretações variadas dos encaminhamentos, da definição do público a ser atendido e de conceitos como tratamento especial contribuiu para a concretização de um processo educativo segregativo. Segundo Carvalho (1997), muitos profissionais interpretaram a expressão "tratamento especial" como atendimento pedagógico terapêutico. Por sua vez, as classes especiais se tornaram espaços educacionais repletos de crianças que não possuíam deficiência, mas, sim, distúrbios de aprendizagem ${ }^{6}$. Nesse contexto, a classe especial surgiu para separar "o bom escolar" dos considerados "anormais". Pode-se observar, no relatório apresentado em 1979 na Assembleia Legislativa, em, que, das 799 crianças atendidas em classes especiais, nem todas seriam crianças com deficiência (PARANÁ, 1979).

Se for considerado que nem todas as crianças atendidas nas classes especiais eram crianças com deficiência, pode-se observar que havia uma tendência de realizar seu atendimento em escolas especiais e programas especiais, pois, em 1978, a quantidade de crianças excepcionais atendidas nessas modalidades foi de 4.157 (PARANÁ, 1979). Outro aspecto que contribuiu para essa afirmativa está expresso nos investimentos realizados pelo setor público na área, assegurando subsídios financeiros, bolsas de estudos, convênios de apoio técnico e cursos de formação e qualificação ao setor privado. Esses fatores revelaram a influência do setor privado na política do CENESP, demonstrando também a disparidade entre o atendimento pelo setor público e a demanda existente, conforme demonstra a citação a seguir:

O percurso histórico da educação especial respondeu a uma série de interesses que podem ser assim sintetizados: crescente privatização quer seja do ponto de vista do número de atendimentos oferecidos, quer pela influência que essas instituições têm exercido; legitimação da escola regular no que tange a imputação do fracasso escolar às características pessoais da criança ou ao seu meio próximo, contribuindo para a manutenção de política educacional que dificulta o acesso ao conhecimento pelos membros das classes subalternas; incorporação de concepções sobre conhecimento científico que sempre tendem universais e transcendentes à própria construção sócio-histórica e que trazem, no âmbito da educação especial, consequências nefastas, na medida em que analisam as possibilidades dos deficientes ou excepcionais somente pela 
via de suas dificuldades específicas; por fim, a educação especial que nasce sob a bandeira da ampliação de oportunidades educacionais aos que fogem da normalidade, na medida em que não desvela os determinantes socioeconômicos e culturais que subjazem às dificuldades de integração do aluno diferente, na escola e na sociedade, serve de instrumento para a legitimação de sua segregação (BUENO, 1993, p. 89-90).

Nesse sentido, promover a expansão da Educação Especial sem considerar as condições materiais de existência dos educandos em uma relação macro do mundo circundante é reproduzir a segregação, para, além disso, atribuir a culpabilidade do fracasso escolar ao próprio indivíduo, em virtude de suas características particularizadas.

O período referente aos anos 1980 foi expressão da crise econômica nacional e internacional, oriunda da crise do petróleo, do aumento das taxas de juros, da repressão do setor industrial e "principalmente pelos encaminhamentos econômicos do regime militar, que deixou como saldo inflação incontrolável, enorme dívida externa, desemprego em massa e concentração de renda, fatores estes que alargaram a distância entre pobres e ricos no Brasil" (HOTZ, 2008, p. 84).

Para esse período, a educação brasileira foi planejada por meio do Plano Setorial de Educação, vigente entre os anos 1979 a 1985, frente às mudanças socioeconômicas desencadeadas pelo fim do nacional-desenvolvimentismo, iniciado na década de 1930 . Hotz (2008) elenca alguns fatores que contribuíram para que a educação brasileira viesse a se configurar de tal modo durante a década de 1980. Um desses fatores foi o aumento da pobreza como consequência do acúmulo de capital e da distribuição desigual da renda, intensificado pelo golpe militar de 1964. Outro fator foi a reorganização política ocorrida após o fim do governo civil-militar, criando a possibilidade de maior participação da população na esfera política, aspecto esse não efetivado. Nesse processo de reorganização política, a educação cumpriu um papel fundamental como política social que postulou a possibilidade de melhoria das condições de vida à população por meio da escolarização.

Hotz (2008) desenvolveu estudos em relação aos seguintes documentos: III Plano Nacional de Desenvolvimento (PND), vigente durante os anos de 1980 a 1985; III Plano Setorial de Educação, Cultura e Desporto (PSECD), vinculado ao MEC e vigente durante os anos de 1980 a 1985; e Diretrizes Setoriais da Secretaria de Estado da Educação, vigentes durante os anos de 1980 a 1983. Tais estudos possibilitam compreender a direção que os governos estavam projetando para a educação como política social:

Constituinte das políticas sociais, a educação desempenhou função ideológica estratégica para o governo do período, que a apontava como necessária para proporcionar a igualdade de oportunidades através da formação, da assistência ao aluno carente, da compra de vagas em estabelecimentos particulares de ensino (bolsas de estudo), e da distribuição de material didático e merenda escolar. Não obstante, a tentativa do Estado em resolver os problemas sociais promovendo renda ao trabalhador brasileiro, ou mesmo proporcionando igualdade de oportunidades através da concessão de bolsas, materiais didáticos e merenda, não rompe com a reprodução e a exploração capitalista, e mais do que isso, as endossa e as reforça (HOTZ, 2008, p. 94).

A educação, nesse sentido, foi tomada como solução para minimizar a pobreza do país e propalar seu desenvolvimento econômico por meio da formação profissional para mão de obra qualificada. Observa-se que, apesar de mudanças conjunturais na década de 
80, mantiveram-se as diretrizes contidas no PND e no PSECD da década de 1970. Nessa lógica, os rumos da Educação Especial continuaram atrelados à política de integração do excepcional no ensino regular, com os encaminhamentos de criação de escolas especiais, de classes especiais e demais atendimentos necessários, ofertando-se apoio técnicofinanceiro a escolas especiais, bolsas de estudos, cursos de qualificação para professores e cursos profissionalizantes aos excepcionais.

O Estado do Paraná, com o objetivo de encaminhar o aluno excepcional para o atendimento adequado, manteve como uma das atividades do DEE o trabalho de triagem e avaliação de alunos que demonstravam necessitar de atendimento especializado. Quanto ao amparo técnico, a SEED continuou com a política de apoio às escolas particulares para o ensino de $1^{\circ}$ grau; na área da Educação Especial, estabeleceu convênio de cedência de professores para regência de classe, com duração de dois anos. Nesse segmento, o cálculo era de um professor a cada oito alunos. No triênio (1979 a 1981), foram cedidos 405 profissionais para atuar na Educação Especial e no ensino de $1^{\circ}$ grau (PARANÁ, 1982).

Nessa perspectiva, registra-se que

O ensino especial é uma responsabilidade social da comunidade, pois o problema de integração do excepcional extrapola a atividade especializada da escola. Por esse motivo, e também para propiciar condições à descentralização da ação governamental no setor, a Secretaria da Educação realizou seminários nas áreas de influência de 11 núcleos regionais de educação - abrangendo 206 municípios - com o objetivo de despertar a consciência das comunidades para os problemas da educação especial. Participaram prefeituras, clubes de serviço, escolas especializadas e de ensino regular, pais e lideranças das comunidades. Como resultado prático imediato dessas reuniões, aumentou o número de municípios com programas específicos de educação e assistência às pessoas portadoras de deficiência (PARANÁ, 1986, p. 60).

A maioria das escolas especiais era particular. Para sua manutenção, recebiam apoio financeiro dos governos estadual e municipal, além da cedência de professores, funcionários e material de consumo. A finalidade do subsídio à Educação Especial das escolas privadas, segundo José Richa (PARANÁ, 1986), era assegurar as mesmas condições de ensino que os demais alunos do ensino regular possuíam (PARANÁ, 1986), razão pela qual o Governo havia destinado, em 1985, orçamento próprio para o DEE.

Em 1987, a estimativa do número de pessoas com deficiência no Paraná, considerando que a proporção de $10 \%$ (OMS) da população possui algum tipo de deficiência, era de 850 mil pessoas. Destas, $50 \%$ encontravam-se na faixa etária de 0 a 19 anos (PARANÁ, 1987). Segundo o governo da época, os excepcionais se dividiam em três categorias: os que tinham condições de estar inseridos no ensino regular e que não precisavam de atendimento especializado (em torno de $30 \%$ a $40 \%$ ); os que deveriam estar matriculados no ensino regular, mas precisavam de um atendimento em programas de Educação Especial; e os considerados portadores de deficiência (uma estimativa de $20 \%$ a 30\%), cujo atendimento deveria ocorrer em instituições especializadas (PARANÁ, 1987).

Pode-se afirmar, portanto, que essa classificação homogeneizou as necessidades e condições educacionais dos portadores de deficiência, representando o pouco conhecimento dos envolvidos na elaboração do relatório apresentado à Assembleia Legislativa em 1987, ou, ainda, expressando a tendência de homogeneizar as necessidades educacionais das pessoas com deficiência. É preciso registrar também que, no ano de 1987, os alunos com múltipla deficiência estavam sendo atendidos em escolas especiais para 
deficientes mentais, cujo agrupamento era organizado de modo adequado às características similares desses alunos.

Frente às mudanças de contexto socioeconômico, a partir da abertura política em 1985, os relatórios começaram a expressar a importância da participação política da população, por meio dos Conselhos Municipais, o que convergia com o encontro do movimento em prol da ampliação de direitos sociais, pautados no estado democrático. As reivindicações dos movimentos das pessoas com deficiência e de entidades representativas desse segmento criaram, no Governo do Estado do Paraná, a necessidade de apresentar relatório com o número de alunos com deficiência matriculados no ensino regular. Esses dados não eram apresentados de forma adequada nos relatórios anteriores, pois, quando se reportavam às escolas especiais, classes especiais e salas de recursos, eles não eram padronizados, e nem sempre eram mencionados.

Assim, é possível apresentar uma estimativa do avanço no atendimento por modalidade (Quadro I). As datas expostas abaixo são aquelas registradas nos relatórios apresentados na Assembleia Legislativa. As informações constantes nesses relatórios sobre a Educação Especial foram obtidas no Departamento de Educação Especial, no CELEPAR e na FUNDEPAR.

Quadro I - Quantitativo de matrículas em classes especiais de instituições públicas e privadas de ensino regular no Paraná, de 1979-1987

\begin{tabular}{|c|c|c|c|c|}
\hline Ano & Público & \% Público & Privado & \% Privado \\
\hline 1979 & 632 & 94,94 & 32 & 5,06 \\
\hline 1980 & 1096 & 95,80 & 46 & 4,20 \\
\hline 1981 & 2235 & 85,32 & 328 & 14,68 \\
\hline 1982 & 1955 & 83,48 & 323 & 16,52 \\
\hline 1983 & 2277 & 93,98 & 137 & 6,02 \\
\hline 1984 & 2151 & 91,96 & 173 & 8,04 \\
\hline 1985 & 2540 & 92,91 & 180 & 7,09 \\
\hline 1986 & 2980 & 89,40 & 316 & 10,60 \\
\hline 1987 & 4041 & 93,24 & 273 & 6,76 \\
\hline
\end{tabular}

Fonte: Quadro elaborado pela autora a partir de dados da SEED/FUNDEPAR (1985 in PARANÁ, 1985) e Paraná $(1986 ; 1988 ; 1989)$

No Quadro I, ao analisar a evolução do número de matrículas em classes especiais de instituições regulares de ensino dos setores público e privado, observa-se que o percentual de matrículas nas escolas públicas variou entre 83 e $95 \%$, enquanto nas escolas privadas o índice percentual foi de, no máximo, 17\%. Tomando-se como exemplo o ano de 1987, a proporção de matrículas entre o setor público e privado foi de aproximadamente 15 para 1.

No Quadro II, são apresentados os números de matrículas realizadas nas instituições especializadas no período que compreende os anos de 1979 a 1987. 
Quadro II - Quantitativo de matrículas em instituições especializadas, de 1979 a 1987

\begin{tabular}{|c|c|c|c|c|}
\hline Ano & Público & \% Público & Privado & \% Privado \\
\hline 1979 & 418 & 11,16 & 3745 & 88,83 \\
\hline 1980 & 427 & 10,29 & 4149 & 89,70 \\
\hline 1981 & 807 & 13,09 & 6164 & 86,90 \\
\hline 1982 & 530 & 10,25 & 5166 & 89,74 \\
\hline 1983 & 510 & 8,82 & 5779 & 91,17 \\
\hline 1984 & 416 & 6,85 & 6071 & 93,14 \\
\hline 1985 & 580 & 8,70 & 6664 & 91,29 \\
\hline 1986 & 851 & 11,54 & 7372 & 88,45 \\
\hline 1987 & 971 & 12,75 & 7614 & 87,24 \\
\hline
\end{tabular}

Fonte: Quadro elaborado pela autora a partir de dados da SEED/FUNDEPAR (1985) e Paraná (1986; 1988; 1989)

No setor público, o número de matrículas era muito inferior ao das escolas especializadas privadas, alcançando, em 1987, seu maior índice de crescimento, que foi de $12,75 \%$. Inversamente às matrículas das classes especiais, as realizadas em escolas especializadas eram predominantemente de instituições privadas, sendo que o percentual alcançado entre os anos de 1979 a 1987 girava em torno de $88 \%$ a 93\%. Nesse período, o número de matrículas variou na proporção de 8 para 1, alcançando, em 1984, a relação de 14 matrículas para o setor privado e de apenas 1 (uma) para o público.

Já o número de alunos matriculados em instituições especializadas em relação aos matriculados em escolas regulares era na proporção de 2 para 1 . Convém ressaltar que os relatórios que apresentam tais questões o fazem sem identificação das áreas atendidas por tipo de deficiência ou outro tratamento especial. Ou seja, o número de matrículas em instituições especializadas e nas classes especiais de escolas regulares não esclarece quantos alunos com deficiência foram atendidos em cada modalidade. Entretanto, os dados possibilitam constatar a tendência de maior crescimento do atendimento das instituições especializadas privadas em relação ao atendimento no setor público.

Também é importante destacar que se observa significativa discrepância ao cruzar os dados acerca do número de instituições especializadas/ano e de classes especiais/ano, compiladas das mensagens dos governadores, com os dados disponíveis no documento intitulado Fundamentos teórico-metodológicos para a Educação Especial (PARANÁ, 1994), que apresenta dados referentes aos programas de Educação Especial que não constam dos documentos disponibilizados pela FUNDEPAR até 1989, sendo que a planilha apresentada compreende o que a SEED tratava como programas de Educação Especial, a saber: Centro de Atendimento Especializado (CAE); Classe Especial (CE); Programa de Educação Especial Supletiva (PEES); Programa de Escolaridade Regular (PER); e Sala de Recursos (SR). Além disso, mencionam-se as áreas de atendimento: Deficiência Auditiva (DA); Deficiência Física (DF); Deficiência Mental (DM); Deficiência Visual (DV); Múltiplo Atendimento (MA); Distúrbios de Aprendizagem (DAp) e Condutas Típicas (CT).

Em relação aos programas de Educação Especial, nas áreas das deficiências, têm-se as classes especiais, datadas a partir de 1977 (15 unidades), principalmente para a área de DM. Já os CAE passam a constar a partir de 1987 para as áreas de DA (37 unidades) e DV 
(66 unidades); quanto à área de DF, o relatório a apresenta como dado somente em 1991 (apenas uma unidade).

Outra análise que julgamos relevante é o comparativo entre a evolução de estabelecimentos de Educação Especial e as de $1^{\circ}$ e $2^{\circ}$ graus do ensino regular. Observa-se que houve um índice de crescimento em torno de 50\%, de 1983 a 1987, em todas as esferas educacionais. Entretanto, observa-se, no Gráfico 1 que o número de instituições privadas é significativamente maior que o de instituições públicas.

Gráfico 1 - Demonstrativo de escolas de Educação Especial nas esferas públicas (federal, estadual, municipal) e particulares no Paraná, de 1983 a 1987

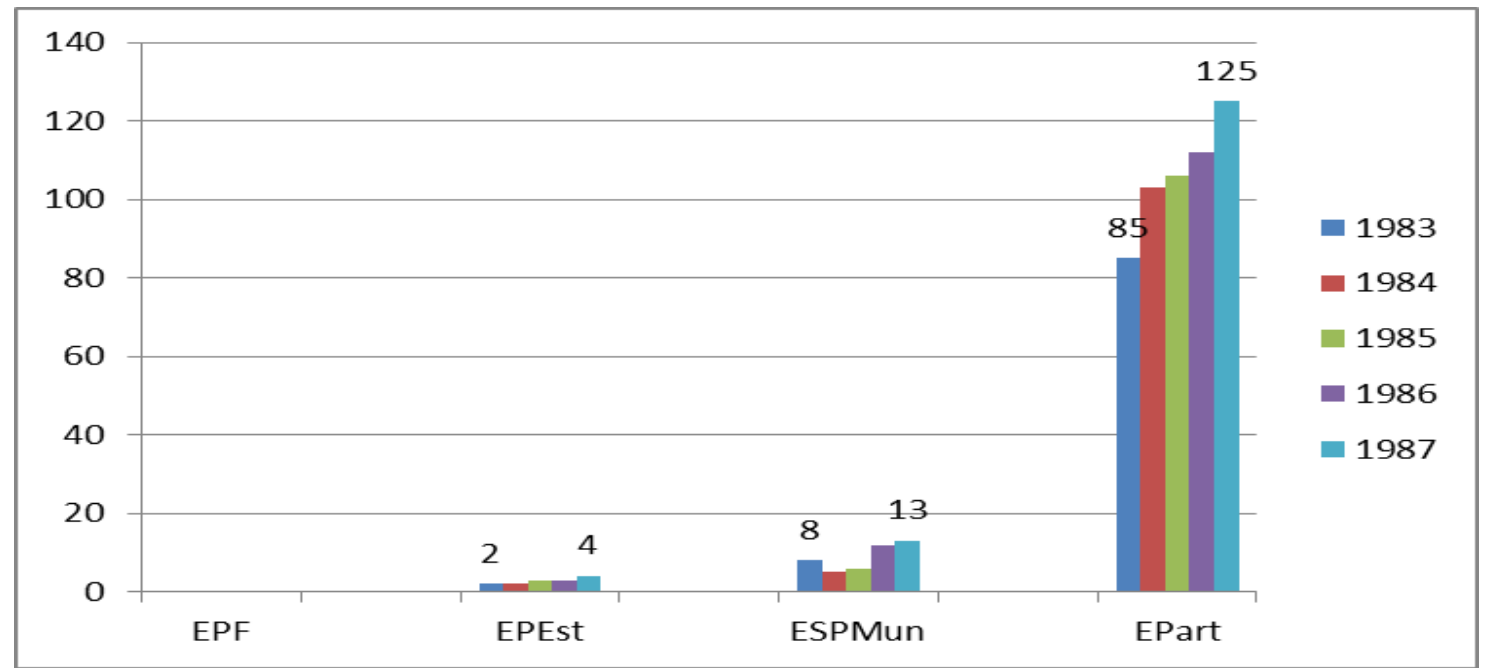

Convenções: EPF $=$ Esfera Pública Federal; EPEst $=$ Esfera Pública Estadual; EPMun $=$ Esfera Pública Municipal; EPart $=$ Esfera Particular (Privada).

Fonte: SEED/FUNDEPAR (1985); Paraná (1986; 1988; 1989)

Ao comparar os dados do Gráfico 1 com os do Gráfico 2, nota-se que a evolução de estabelecimentos de ensino regular é oposta em relação à Educação Especial. Considerando o período de 1983 a 1987, constata-se que, enquanto na Educação Especial da rede regular na esfera estadual houve aumento de duas para quatro unidades, e na esfera municipal, de oito para treze escolas, no setor privado, as escolas especiais aumentaram de 85 para 125 unidades. Considerando a capacidade de investimento do Estado do Paraná, entre 1983 e 1987, pode-se afirmar que o crescimento de unidades escolares na esfera pública foi irrisório, aumentando apenas de duas para quatro unidades. Nesse aspecto, cabe aqui ressaltar, parafraseando a afirmação do professor Bueno (proferida na Mesa Redonda intitulada Perspectivas para a Educação Especial no Brasil: Política e Práticas, em 17 de novembro de 2012, durante a V CBEE, promovida pela UFSCAR, que as escolas especializadas só sobrevivem devido à "omissão" do Estado e, consequentemente, do financiamento público.

\section{Considerações finais}

Diante do histórico traçado neste estudo, observa-se que, segundo Canziani (1985), tanto o setor público como a iniciativa privada já vinham atuando nessa área e trabalhando de modo conjunto. Entretanto, a autora afirma que, até o ano de 1963, as ações educacionais para esse segmento ocorreram de forma esparsa e isolada, sem uma ação 
governamental que definisse metas, diretrizes e normas. Os atendimentos eram mantidos pelos fundadores dos serviços, com auxílios da comunidade e por eventuais contribuições oficiais. Nesse sentido, foram a partir das experiências vivenciadas pelos Estados e pela necessidade posta pelas escolas especiais e pela comunidade que o governo federal deu continuidade ao postulado da LDB $n^{\circ} 4.024$ (BRASIL, 1961) a respeito da educação das pessoas com deficiência. Essas ações estavam alinhadas às mudanças sócio-políticas e econômicas nacionais e internacionais que estabeleceram os princípios da normalização, individualização, integração e racionalização, os quais estavam presentes nos planos nacionais e estaduais de educação, e, por conseguinte, na Educação Especial.

O Estado brasileiro formalizou as modalidades (público ou privado) de atendimento ao deficiente com a LDB $\mathrm{n}^{\circ}$ 4.024/1961. Nessa legislação, ficou definido que o ensino para este segmento deveria ocorrer, preferencialmente, no ensino regular, mas também deveria ficar aberto às instituições privado/filantrópicas, com apoio técnico-financeiro do Estado. Nesse sentido, essa LDB consagrou o modelo que já vinha sendo realizado no país. Alunos como alguns cegos estudavam nas escolas regulares, enquanto as pessoas com deficiência mental estavam nas escolas especiais.

Neste contexto, a Educação Especial ocorrida nas décadas de 1970 e 1980 foi fruto de uma estrutura constituída historicamente, sendo que, em sua forma organizacional, havia as classes especiais, as escolas especializadas e os institutos. Nesse período, a LDB de 1961 foi substituída pela Lei ${ }^{\circ} 5.692$ (BRASIL, 1971). Cabe evidenciar que o discurso de expansão da Educação Básica permeava também a Educação Especial, porém, com um diferencial crucial: enquanto a expansão da Educação Básica do ensino regular era fomentada por meio do ensino público e por escolas privadas, na Educação Especial, a expansão ocorria, principalmente, pelo crescimento das instituições privadas/filantrópicas com apoio técnico-financeiro do Estado.

Tanto a Lei $\mathrm{n}^{\circ} 4.024 / 61$ como a Lei $\mathrm{n}^{\circ} 5.692 / 71$ previam a possibilidade de apoio técnico-financeiro para qualquer instituição privada. O fato é que, para os alunos considerados normais, as bolsas estavam vinculadas às escolas particulares, que, em tese, ofereciam uma educação de melhor qualidade. Por outro lado, para os considerados excepcionais, as bolsas de estudos estavam direcionadas às escolas especializadas, em que, devido à concepção de pessoa com deficiência, o cuidado e a proteção eram exacerbados.

Ao considerar as políticas de apoio técnico-financeiro às instituições privadas, pode-se fazer um comparativo do avanço entre o setor público e o privado, sendo que a relação entre o ensino regular e o especial é inversamente proporcional: a expansão do ensino regular se deu no setor público, ao passo que a Educação especial se expandiu nas escolas filantrópico-assistencialistas.

Finalmente, pode-se concluir que o desenvolvimento da proposta de Educação Especial implantada pelo Estado do Paraná estava alinhada à política do CENESP, a qual considerou, em suas recomendações, a possibilidade de o aluno com deficiência estudar no ensino regular com apoio do atendimento especializado. Porém, a metodologia empregada contribuiu principalmente para a ampliação e manutenção das escolas e classes especiais, fato este que demonstrou como o Estado, como interventor, respondeu às reivindicações dos movimentos sociais, ao mesmo tempo em que assegurou o interesse do capital.

Independente do locus de atendimento, as barreiras proporcionadas por princípios religiosos e conceitos pautados no aspecto biológico contribuíram para o processo segregativo sofrido pelas pessoas com deficiência. Além disso, este estudo possibilitou compreender quais princípios e conceitos científicos, filosóficos e pedagógicos estavam presentes na proposta de integração, os quais também se encontravam, ainda que com novas reformulações, na proposta de inclusão, como por exemplo: formação de professores 
na área da Educação Especial, adaptação do ambiente físico, provimento de recursos didáticos, participação no sistema geral de ensino, atendimento especializado e escolas especiais. Desse modo, frente à concepção de pessoa com deficiência presente nas propostas de currículo (BRASIL, 1979a; 1979b; 1979c; 1979d) para as pessoas com deficiência, a expansão do atendimento em escolas especiais superou o atendimento no ensino regular.

\section{Referências}

BRASIL. Senado Federal. Lei de Diretrizes e Bases da Educação Nacional. Lei n. $^{\circ} 4.024$, de 20 de dezembro de 1961. Fixa as Diretrizes e Bases da Educação Nacional. Brasília: 1961. Disponível em: <http://www.planalto.gov.br/ccivil_03/LEIS/L4024.htm>. Acesso em: 30 maio 2012.

. Senado Federal. Lei de Diretrizes e Bases da Educação Nacional. Lei n. $^{\circ}$ 5.692, de 11 de agosto de 1971. Fixa as Diretrizes e Bases para o ensino de $1^{\circ}$ e $2^{\circ}$ graus, e dá outras providências. Disponível em: <http://www.pedagogiaemfoco.pro.br/15692_71.htm>. Acesso em: 30 maio 2012.

Presidência da República. Decreto $n^{\circ} 72.425$, de 3 de julho de 1973. Cria o Centro Nacional de Educação Especial (CENESP), e da outras providências. Brasília/DF, 1973.

Diretrizes básicas para ação do Centro Nacional de Educação Especial. (Extraídas do Projeto Prioritário n. 35 - Educação Especial do Plano Setorial de Educação e Cultura. 1972/1974). Brasília/DF, 1974.

Ministério da Educação e Cultura. Centro Nacional de Educação Especial CENESP. Proposta curricular para deficientes visuais. Volume I. Elaboração: Universidade do Estado do Rio de Janeiro. Convênio CENESP-PREMEN. Brasília, DF: Departamento de Documentação e Divulgação, 1979a.

Ministério da Educação e Cultura. Centro Nacional de Educação Especial CENESP. Proposta curricular para deficientes visuais: Manual do professor. Volume IV. Elaboração: Universidade do Estado do Rio de Janeiro. Convênio CENESP-PREMEN. Brasília, DF: Departamento de Documentação e Divulgação, $1979 b$.

Ministério da Educação e Cultura. Centro Nacional de Educação Especial CENESP. Proposta curricular para deficientes mentais educáveis. Volume I. Elaboração: Universidade do Estado do Rio de Janeiro. Convênio CENESP-PREMEN. Brasília, DF: Departamento de Documentação e Divulgação, 1979c.

. Ministério da Educação e Cultura. Centro Nacional de Educação Especial CENESP. Proposta curricular para deficientes auditivos. Volume I. Elaboração: Universidade do Estado do Rio de Janeiro. Convênio CENESP-PREMEN. Brasília, DF: Departamento de Documentação e Divulgação, 1979d.

. História do Movimento Político das Pessoas com Deficiência no Brasil. Compilado por Mário Cléber Martins Lanna Júnior. - Brasília: Secretaria de Direitos Humanos. Secretaria Nacional de Promoção dos Direitos da Pessoa com Deficiência, 2010. 
BUENO, J. G. S. Educação Especial brasileira: integração/segregação do aluno diferente. São Paulo: EDUC; PUC/SP, 1993.

CANZIANI, M. L. B. Educação Especial: visão de um processo dinâmico e integrado. Curitiba: Educa, 1985.

CARVALHO, R. E. A nova LDB e a Educação Especial. Rio de Janeiro: WVA, 1997.

GONÇALVES, N. G. Desenvolvimentismo e educação no Paraná (décadas de 1969 e 1970). Diálogos, Maringá, v. 1, n. 1, p. 143-171, 1997.

HOTZ C. Estado e política educacional no Brasil (1979 a 1989). 200 f. Dissertação (Mestrado em Educação) - Universidade Estadual do Oeste do Paraná, Cascavel, 2008.

PARANÁ. Governo do Estado do Paraná. Mensagem apresentada à Assembleia Legislativa do Estado por ocasião da abertura da $3^{a}$ Sessão Ordinária da $4^{a}$ Legislatura pelo Senhor Ney Aminthas de Barros Braga. Curitiba, 1961.

Decreto $\mathrm{n}^{\circ} 10.527,11$ de janeiro de 1963. Atos do Poder Executivo. Diário Oficial do Estado. Curitiba, 11 jan. 1963.

Governo do Estado do Paraná. Conselho Estadual de Educação. Lei $n^{\circ} 4.978$, de 5 de dezembro de 1964. Estabelece o Sistema Estadual de Ensino. Curitiba, 1964.

Governo do Estado do Paraná. Mensagem apresentada à Assembleia Legislativa do Estado pelo Senhor Jayme Canet Junior. Curitiba, 1977.

Governo do Estado do Paraná. Mensagem apresentada à Assembleia Legislativa do Estado pelo Senhor Jayme Canet Junior. Curitiba, 1978.

Governo do Estado do Paraná. Mensagem apresentada à Assembleia Legislativa do Estado pelo Senhor Jayme Canet Junior. Curitiba, 1979.

Governo do Estado do Paraná. Mensagem apresentada à Assembleia Legislativa do Estado pelo Senhor Ney Aminthas de Barros Braga. Curitiba, 1980.

. Governo do Estado do Paraná. Mensagem apresentada à Assembleia Legislativa do Estado pelo Senhor Ney Aminthas de Barros Braga. Curitiba, 1982.

Governo do Estado do Paraná. Mensagem apresentada à Assembleia Legislativa do Estado pelo Senhor José Richa. Curitiba, 1985.

Governo do Estado do Paraná. Mensagem apresentada à Assembleia Legislativa do Estado pelo Senhor José Richa. Curitiba, 1986.

. Governo do Estado do Paraná. Mensagem apresentada à Assembleia Legislativa do Estado pelo Senhor João Elisio Ferraz de Campos. Curitiba, 1987.

. Governo do Estado do Paraná. Mensagem apresentada à Assembleia Legislativa do Estado pelo Senhor Álvaro Dias. Curitiba, 1988.

. Governo do Estado do Paraná. Mensagem apresentada à Assembleia Legislativa do Estado pelo Senhor Álvaro Dias. Curitiba, 1989.

- Secretaria de Estado da Educação. Departamento de Educação Especial. Fundamentos teórico-metodológicos para a Educação Especial. Curitiba: SEED/DEE, 1994.

TRINTIN, J. G. A nova economia paranaense: 1970-2000. Maringá: Eduem, 2006. 


\footnotetext{
${ }^{1}$ Mestre em Educação. Pedagoga. Coordenadora do Programa Institucional de Ações Relativas às Pessoas com Necessidades Especiais (PEE) da Universidade Estadual do Oeste do Paraná (UNIOESTE). Membro dos grupos de Pesquisas História, Sociedade e Educação no Brasil - Grupo do Oeste do Paraná (HISTEDOPR), e Estudos Marxistas em Educação.

${ }^{2}$ Doutor em Educação. Docente da Universidade Estadual do Oeste do Paraná (UNIOESTE). Líder do Grupo de Pesquisa História, Sociedade e Educação no Brasil - Grupo do Oeste do Paraná (HISTEDOPR).

${ }^{3}$ Mestre em Engenharia de Produção. Psicólogo. Coordenador do Centro de Reabilitação Física da Universidade Estadual do Oeste do Paraná (UNIOESTE). Membro do Programa Institucional de Ações Relativas às Pessoas com Necessidades Especiais (PEE) da UNIOESTE.

${ }^{4}$ Neste texto, as palavras relativas à terminologia sobre deficiência empregada no período pesquisado estão destacadas em itálico.

${ }^{5}$ Foram consultadas as mensagens disponíveis no site referentes aos anos de 1970, de 1977 a 1979, de 1980 a 1983 e de 1985 a 1989. Disponível em:

http://www.arquivopublico.pr.gov.br/modules/conteudo/conteudo.php?conteudo=31. Acesso em: 14 jul 2012.

${ }^{6}$ Rosita Edler Carvalho, em seu livro A nova LDB e a Educação Especial (1997), faz uma análise de aspectos das leis na efetivação da política de Educação Especial. Nas páginas 66 e 67, a autora explicita o problema em relação às classes especiais e a seu uso desvirtuado.
}

Recebido: junho-15 Aprovado: outubro-15 